\title{
Research on the Cultural Intermediary Organizations in China: Present Developing Situation, Predicament and Improvement Methods
}

\author{
Shaogang Liao, Songdan Yi, Jiayi Zhong \\ School of Public Finance and Public Administration, Jiangxi University of Finance and Economics, Nanchang, China
}

Email address:

liaoshaogang@163.com (Shaogang Liao)

\section{To cite this article:}

Shaogang Liao, Songdan Yi, Jiayi Zhong. Research on the Cultural Intermediary Organizations in China: Present Developing Situation, Predicament and Improvement Methods. Journal of Human Resource Management. Vol. 5, No. 3, 2017, pp. 45-52.

doi: 10.11648/j.jhrm.20170503.11

Received: March 19, 2017; Accepted: March 29, 2017; Published: July 4, 2017

\begin{abstract}
In recent years, the cultural department of our government has been doing a lot of explorations on policy-making, mechanism innovation and market completion, in order to introduce market factors, promote the prosperity and development of cultural industry. As one of the cultural industry market subject, the culture intermediary organizations plays an important role in completing the cultural market operation system, guiding the public cultural products consumption, promoting cultural products trade. The cultural industry developing is indispensable to the standardized operation of cultural intermediary organizations. Integrating the recent years per capita cultural establishment expense, cultural market scale, market business units and the construction of cultural institutions, This paper analyses the current status of the development of cultural industry in China as well as the important factors restricting the development of cultural intermediary organization in our country. Finally, putting forward some Suggestions to promote the development of the cultural intermediary organization in our country from the aspect of perfecting system construction, transforming government functions, building the information sharing platform and establishing cultural talent cultivation mechanism, etc.
\end{abstract}

Keywords: Cultural Industry, Cultural Intermediary Organizations, Development Predicament, Improvement Methods

\section{Introduction}

Since 2009, when China promulgated the first cultural industry specialized planning--China's Cultural Industry Promotion Plan, the cultural industry has developed rapidly in our country and achieved rich results in the filed of cultural products production, cultural art services, cultural creativity design as well as mass cultural consuming, etc. In the process of comprehensively deepen reform in our country, the third plenary session of the eighteenth--"certain major issue decision of the central committee of the communist party on comprehensively deepen the reform", putted forward to promote culture system and mechanism innovation, which establishes and improves the modern cultural market system, improves the level of culture industry scale, intensive, specialization and encourages the financial capital and combination of social capital, cultural resources, promotes the cultural information and the free flow of resources across the country, and establishes a multilevel cultural product and factor markets.

As a service organization, the cultural intermediary organizations provides the information for both supplies and contributes to cultural products trade charging for a commission, whose main function is to reduce the information asymmetry of cultural market and implement cultural market information exchange and sharing. At the present stage of deepening reform of market economic system and strengthening the decisive role of market mechanism in the allocation of resources, the cultural development of intermediary organization plays an important role to promote the rapid development of cultural industry. Cultural intermediary organizations, as the service organization that connects the cultural enterprise service, products circulation and cultural consumption and so on. It is an important bridge between governments, cultural enterprises and institutions, consumers and the market communication. Due to cultural intermediary organizations developing in China started 
relatively late and with a small scale, lacking sound policies and regulations to support and guide it; so it meets many bottlenecks in the process of development that the development speed is slow. In addition, currently our country academic circles lack of deep research on cultural intermediary organizations. Therefore, strengthening the research of Chinese cultural intermediary organization development has a very important practical significance and theoretical value.

\section{The Function of Cultural Intermediary Organization}

As the service organizations, cultural intermediary organizations charge for a commission by providing the information for both supplies and facilitating cultural products and service trades. Cultural intermediary organizations make a profit mainly by means of cultural information superiority and cultural service in cultural market, so as to promote their own development and perfection. There are many different kinds of cultural intermediary organizations involved in all aspects of the cultural fields, such as cultural information services, cultural entertainment career and cultural product design and promotion, cultural activities equipment and technology supply, talent cultivation and so on. The cultural intermediary organizations plays a vital role in promoting the development of cultural industry and market.

(1) Reduce the Transaction Costs of Cultural Products, Meet Diversified Market Demand

In the process of cultural products market transaction, both parties have to pay the advance of product costs including collecting information from the market, products investigation, negotiation and decision-making costs, the formulation and implementation plan costs. Even they will pay the game costs in a important trade. In the process of cultural products and service trade, the high information costs is an important factor influencing the cultural products trade. As the information service organization, the cultural intermediary organizations can reduce the cultural products market transaction costs from the following aspects: reducing information collection costs, reducing the matching search costs and inhibition adverse selection, etc.

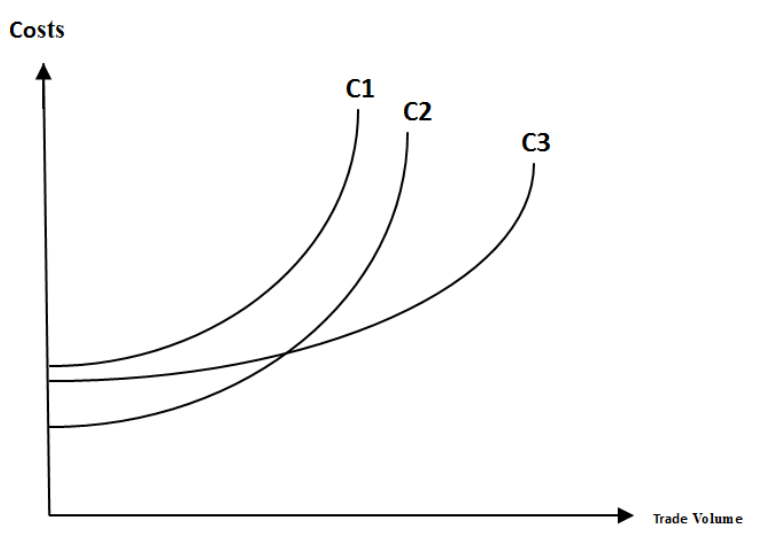

Figure 1. Cultural products trade costs-trade volume.
As shown in figure 1, C1 represents the cost of cultural product demand direct purchasing inputs, including trade cost and organization cost; $\mathrm{C} 2$ is the organization costs of the demand side production inputs. It has a fixed costs lower than $\mathrm{C} 1$ and has a higher management efficiency than $\mathrm{C} 1$; $\mathrm{C} 3$ shows the purchasing factors input costs of cultural intermediary organizations. Under the effect of cultural intermediary organizations, the supply and demand of both sides only need to pay the fees or pay in some way can get the corresponding cultural information; as long as the commission is lower than its collect information costs, the cultural products transaction bridging by cultural intermediary organizations can occur. Information provided by cultural intermediary organizations can make the market resources allocation of transactions costs fell below the cost of enterprise internal organization resources configuration. At the same time, the advantage of cultural intermediary organizations is to provide the market transaction platform, in order to reduce the uncertainty of the two sides of supply and demand information search and its high costs. This kind of intermediary service can give full play to the role of market mechanism and meet the market demand of diverse cultures.

(2) Promote the Cultural System Reform, Optimize the Resources Allocation of Cultural Market

Influenced by traditional planned economy system, China's cultural enterprises and cultural market often suffer from the government's administrative interference and the bureaucratic system has many disadvantages. In the process of developing socialist market economy in China and with the deepening of market mechanism, government shift from directly running cultural enterprises to cultural enterprises management and service. Since then, China's cultural enterprises have become a market entity with self-financing, self-development, self-restraint. Cultural intermediary organizations were born and grew stronger in the environment of economic system reform and diversified development of cultural demand, which promoted the reform of cultural system in our country, speed up the transition of the government culture function, optimized the resources distribution of the cultural market. As the market intermediary organization, cultural intermediary organizations take the fair, justice, and equality as its activity guidelines. It is responsible for part of economic and cultural management function of government's administrative reform, making the government departing from the micro management, focusing on strengthening the macro management of cultural industry. As an important subject of the cultural market, the cultural intermediary organizations provide a rich market mechanism for the cultural enterprises' resource allocation (cultural talents, capital, technology, property rights, copyright, etc.) and promote the rational allocation of cultural market resources.

(3) Improve and Standardize the Cultural Market, Build up the Modern Cultural Market System

With the deepening of the transformation of government functions from direct management to indirect management, cultural intermediary organizations will play an important 
role in improving and standardizing the cultural market by the virtue of independence, market and professional. Its "media" function would be beneficial to strengthen the diversification of cultural information dissemination, promote the circulation and trade of cultural products, promote rational and efficient allocation of cultural resources, reduce the transaction costs of cultural products, improve the vitality of the cultural market, and create favorable conditions for the development of cultural industries. Secondly, the cultural intermediary organizations, directing to the market consumer groups, can accurately grasp the diverse needs of the cultural market; and through information and organizational advantages, it makes the best use of fostering cultural consumer groups, expand the cultural industry market and promote cultural and economic consumption. In addition, in the cultural market, cultural intermediary organizations also play the role of supervisor which supervises the services of cultural enterprises, deals with contradictions and disputes in the cultural market, coordinates the interests of government departments, market culture subjects and other economic subjects, regulates the economic order of the cultural market. As a product of the development of market economy in a certain stage, on the one hand, the cultural intermediary organizations can improve and regulate the cultural industry market's organizational structure and operational mechanism; on the other hand, it also can integrate different kinds of scattered, fragmented cultural market entities together and build up cross-industrial, cross-regional cultural market organizations, attract social capital to join in, establish a mixed ownership of the cultural market mechanism, promote the establishment of modern cultural market system.

(4) Promote the Participation of All the People in Cultural Construction, Elevate People's Cultural Quality

Cultural intermediary organizations belong to social organizations, with the characteristics of social, non-governmental. In the cultural market, It has become the third largest engine besides governmental organizations and cultural enterprises. The development of cultural intermediary organizations can not only enrich the main body of cultural market, but also strengthen the power of cultural market. Cultural intermediary organizations gradually participate in China's social and cultural undertakings and the development of cultural industries with the identity of social forces. In addition, the construction of modern cultural market system in China should give full play to the wisdom and strength of broad masses of the people; fully mobilize initiative, active and creativity of the all sectors of society to participate in cultural construction. While cultural intermediary organizations are characterized by social and market feature and can efficiently promote cultural products trade, disseminate cultural information, cultivate cultural consumer groups, guide cultural consumption and other functions for the public to participate in cultural construction platform. Therefore, the development of cultural intermediary organizations can make the public have more chance to contact with the cultural products, enjoy more cultural services, improve the cultural quality of the people. At the same time, providing the public more quantity and higher quality cultural products and services, which can enhance the enthusiasm of public participation in the cultural construction and contribute themselves into the development of cultural industries.

With the rapid development of China's economy since the reform and opening-up, along with the consumption of resources and the destruction of the environment, the carrying capacity of China's economic development has weakened. The role of the first industry and the second industry to promote China's economic growth gradually slowed down. As the tertiary industry, cultural industry is the key industry our government has cultivated in recent years. It is also an important force to promote the transformation and upgrading of China's economic development and a key factor to improve the national cultural soft power. Only the country with strong competitiveness of the cultural industries and cultural markets can occupy a place in the international cultural market. Cultural intermediary organizations play a propellant role in the development of China's cultural industry. Due to the professional competence and efficient service of cultural intermediary organizations, it has advanced cultural information resources, and advanced international information resources in foreign cultural exchanges; bring more opportunities for the domestic cultural industry development innovation; that is conducive to the promotion of culture and enhance the country's soft power.

\section{The Current Status of China's Cultural Industry}

(1) Investment in Cultural Undertakings Continually Increasing

In recent years, the investment in cultural undertakings has increased continually in our country. The national cultural undertakings expense reaches 52.049 billion yuan by 2014, an increase of 5.039 billion yuan over the previous year, an increase of $10.5 \%$; national per capita cultural expenses 43.01 yuan, an increase of 4.02 yuan over the previous year, $10 \%$ increasing, as shown in figure 2 :



Data source: China's cultural industry development report in 2014

Figure 2. China's per capita cultural operating expense from 2005 to 2014.

According to the data in figure 2, the total expenditure is increasing year by year, and the level of cultural consumption 
of the residents is gradually increasing. This is a significant impetus to promote the development of related cultural undertakings in China. In 2013, China's cultural sector approved 2159 foreign cultural exchange projects and 66338 people participated it; Compared with previous years, this is a huge number. In order to make China's cultural industry go abroad, some market institutions like cultural intermediary organizations have been developed rapidly.

(2) The Cultural Market Scale Increasing
According to the data from the Chinese Academy of Social Sciences releasing "China's cultural industry development prospects and industrial chain investment opportunities analysis report", Since 2006, China's cultural industry added value shows a rising trend, and the development is relatively stable; in 2014, China's culture and related industries added value is 2405.9 billion yuan, an increase of $14.56 \%$. As shown in figure 3 :

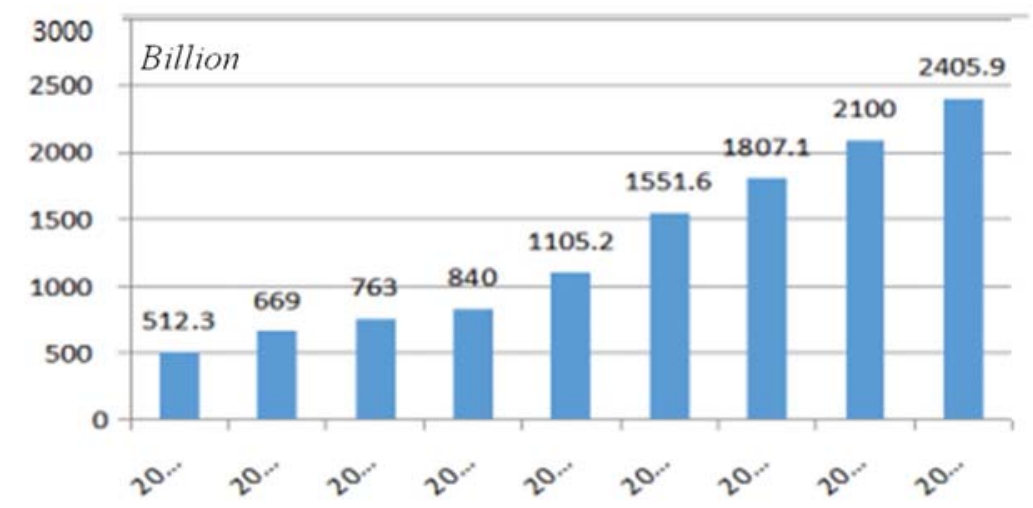

Data source: China's cultural industry development prospects and industrial chain investment opportunities analysis report.

Figure 3. China's culture and related industries added value.

According to the data in figure 3 , we can see that our government has paid more and more attention to the development of cultural industry. The value-added of culture and its related industries have been increasing, and the scale of our cultural market is expanding day by day. With the rapid development of China's cultural industry, the number and scale of cultural intermediary organizations are also expanding; the proportion of revenue from cultural products and services market transactions is also increasing day by day.

(3) Cultural Organizations Grows Continually

With the rapid development of China's social economy, the public demand for cultural products is getting higher and higher. Similarly, the cultural market demand for cultural organizations is also increasing. There for, in recent years, it is the rapid expansion period of cultural organizations, when the cultural institutions financial allocations is also on the rise which is granted by the national state.

Table 1. Development of funds and construction projects of Chinese cultural institutions.

\begin{tabular}{|c|c|c|c|c|}
\hline & Income (Billion yuan) & Expenditure (Billion yuan) & $\begin{array}{l}\text { Financial allocation income } \\
\text { (Billion yuan) }\end{array}$ & $\begin{array}{l}\text { Capital construction projects } \\
\text { (Billion yuan) }\end{array}$ \\
\hline In 2012 & 31.7 & 30.6 & 19.9 & 162.6 \\
\hline In 2013 & 38.4 & 37.7 & 24.8 & 419.5 \\
\hline In 2014 & 44.1 & 43.4 & 29.2 & 980.9 \\
\hline
\end{tabular}

Data source:China's cultural industrial development report in 2015

From table 1, the number of cultural organizations in China increases year by year, but China's cultural industry is in a stage of rapid development and the number of cultural organizations is far from saturated.

According to the statistics of the cultural development of China's Ministry of Culture in 2014, the number of cultural market units is 22.66 million and the number of employees is 1.4518 million. The operating income of cultural market operators is 136.657 billion yuan and the total profit is 35.174 billion yuan. The specific distribution of operating units in each region is shown in Table 2:

Table 2. Main indicators of China's cultural market business unit by region in 2014.

\begin{tabular}{lllll}
\hline & Organization number & Employee number & Total income (Billion yuan) & Total profit (Billion yuan) \\
\hline Amount(proportion) & 226584 & 1451818 & 136.657 & 351.74 \\
City & 83836 & 64245 & 62.589 & 16.813 \\
& $(37.0 \%)$ & $(44.2 \%)$ & $(45.8 \%)$ & $(47.8 \%)$ \\
County & 90860 & 612512 & 49.743 & 13.261 \\
& $(40.1 \%)$ & $(42.2 \%)$ & $(36.4 \%)$ & $(37.7 \%)$ \\
Township \& village & 51888 & 196849 & 24.325 & 5.1006 \\
& $(22.9 \%)$ & $(13.6 \%)$ & $(17.8 \%)$ & $(14.5 \%)$ \\
\hline
\end{tabular}


In 2014, the number of China's cultural and entertainment industry organizations was 89,652, and the number of employee was 835,700 , an increase of $7 \%$ over the previous year. The total operating income of the whole year is 88.421 billion yuan, $46.2 \%$ over the previous year; The profits is 20.847 billion yuan, an increase of $5.2 \%$. The prosperity of these cultural industries are promoting the development of China's cultural intermediary organizations. But our cultural intermediary organizations encounter a lot of difficulties on the development road, when all aspects of the conditions are not very mature.

\section{The Current Development of China's Cultural Intermediary Organizations Predicament}

China's cultural intermediary organizations origins from the 1980s, after the development of 30 years reform and opening up, it plays an important role in promoting China's cultural industries development. Compared with the western developed countries, the development of cultural intermediary organizations in China starts relatively late; the government cultural departments have assumed too much cultural management functions, and the development space of cultural intermediary organizations has been restricted, hindering its effective development. The developmental dilemma of the cultural intermediary organizations in our country is mainly manifested in the following aspects:

(1) Policies and Regulations Absence, Social Trust Mechanism Lacking

The current market economy system in our country is socialist market economic system and it is the legal economy. The orderly competition is the basis for the healthy development of cultural intermediary organizations. But at present, the laws and regulations of cultural intermediary organizations in our country are imperfect, leading to lack of normative operation and management of cultural intermediary organizations, especially lacking a set of authoritative standards for practitioners. There are no clear regulations about the intermediary organizations in the service charges, policy support and taxation, only a few scattered government departments rules. And lacking the protection of laws and regulations will lead to vicious competition within the cultural intermediary services industry, thus hindering the comprehensive development of cultural intermediary organizations. Secondly, there are serious trust crisis in our current society, and some cultural intermediary organizations choose unscrupulous means in order to obtain short-term interests, which leads to unfair competition. These behaviors will have a negative impact on China's cultural industry. Because of the absence of clear regulation and guidance of the laws and regulations, cultural intermediary organizations cannot establish a trust mechanism to promote organizational operations, which leads to a lack of public understanding of cultural intermediary organizations and trust. And the social recognition of cultural intermediary organizations is not very high, which increases the additional costs in the process of providing cultural services and affects the cultural intermediary organization's service efficiency. Therefore, perfecting the laws and regulations and clarifying the legal status and social function of cultural intermediary organizations are most urgent problems to be solved.

(2) Much Government Control and Poor Market Competitiveness

Under the influence of the traditional administrative system and the economic regulation and control, the degree of the government's intervention of the market economy is still high; The cultural industry has been regarded as the national ideology-oriented industry, so the development of the cultural industry has also become one of the most important areas under the government's control. Government departments are more cautious in approving and auditing the establishment of cultural intermediary organizations as well as in the areas of cultural intermediary organizations participating in cultural construction. For a long time, government departments, as the controller of cultural resources, have the right to allocate resources for the development of cultural industries. Government departments often favor the use of more cultural resources in official cultural organizations, and more prefer official cultural organizations in cultural industry policy-making. While the civil intermediary organizations haven't received the attention it deserves in the process of cultural industry development and government cultural products transaction. The shortcoming of cultural intermediary organizations as the main body of the market cultural development restricts the development space and market competitiveness of the cultural intermediary organizations in China in policy supporting, resource acquisition and information collection. As a result, the cultural intermediary organization survival between the government culture department and the official culture enterprise "crack" at long-term; The function of cultural intermediary organizations and its' market potential don't get a effectively use, hindering the healthy development of cultural industries. As government departments does not clear their roles and positioning in the fulfillment responsibilities of the cultural industry development, the functional offside behavior emerges. The administrative interference of cultural industry development and the preference of policies and resources in some cultural intermediary organizations operation hinder the orderly and healthy development of cultural intermediary organizations, limit the development of cultural intermediary organizations space, and curb the cultural intermediary organizations, market vitality and competitiveness.

(3) Poor Information Collection Ability, Weak Operation and Management Ability

In the process of deepening the economic system reform, the traditional industry is facing the pressure of transformation and upgrading. As the social service organization aiming at reducing the information cost of the 
cultural product transaction, the cultural intermediary organization reduces transaction costs by lowering the degree of information asymmetry between the trade parties and the both sides of business uncertainty. Therefore, the ability to collect information is very important for the cultural intermediary organizations; but because of the late development of our cultural intermediary organizations, supervisor mode is relatively backward; there are many development institutional barriers and lacking of information management system, don't establish the innovative information management network, information collection means and way behind, leading to the low ability to collect information. As a market intermediary and social service organizations, cultural intermediary organizations, self-management and management capacity are also very important. In the process of cultural market transactions, different market players have diversified needs, and the demand for information acquisition is also diversified. Due to the low degree of marketization of cultural intermediary organizations in China, there is a lack of initiative to understand the needs of cultural market players, leading to self-improvement and operation and management capacity is weak, limiting the cultural intermediary organizations, self-innovation and self-development.

(4) Talent Scarcity of Cultural Intermediary, Poor Quality of Employees

Cultural talent is one of the important elements of the cultural market, can bring a steady flow of power for the development of cultural intermediary organizations. However, at present, China's cultural intermediary organizations are still relatively lack of high-level talent, lacking a standardized qualification requirements of employees. In China, except some large-scale cultural intermediary organizations, many employees who are engaged in cultural industry work are not professional. They lack of high cultural quality and professional competence. At present, the development level of some cultural intermediary organizations in China is low, so that practitioners do not need to have the appropriate professional basis and ability; they can only be trained through simple induction that is often mere formality or not professional. As a result, that makes the quality of Chinese cultural intermediary organizations and the ability of employees not high and leading to cultural intermediary organizations and lacking innovative capacity. In addition, universities in our country have not set up relevant courses on cultural intermediary organizations, which reflects the lack of cultural intermediary personnel training system; this directly leads to lacking the cultural talents guaranteeing in the the development of cultural intermediary organizations demand.

\section{Suggestions on Perfecting the Development of Cultural Intermediary Organizations in China}

In recent years, scholars have suggested that the government should return the power to market. The cultural market needs a free competitive environment to play its market potential in order to contribute to the prosperity and development of cultural industry. China's cultural intermediary organizations are still facing many development dilemmas, which need to be perfected from the aspects of system arrangement, system construction, self-construction and personnel training.

(1) Perfecting the Cultural Intermediary Organizations Code of Conduct, Improving the Institutional Environment

The majority of industries developing to a certain stage will form a set of industry norms or laws and regulations that complied by industry practitioners, so as to maintain the development of the industry operation order. As the development of cultural intermediary organizations in China started late, the operating mechanism is not perfect, so the need to establish a unified industry norms and regulations to maintain the healthy development of cultural intermediary organizations. These codes of conduct and regulations can be established by usage within the industry or it can be issued by the relevant departments of the administrative provisions (such as regulations, codes, methods, etc.). For example, in 2012, China Association of Performing Managers officially changed its name to China Performing Guild (overseen by the Ministry of Culture), and accordingly introduced a series of rules and codes to regulate their industry behavior, such as performing brokers management practices, temporary internet culture management regulations, brokers management practices, business performance management methods and so on.

In addition, to improve the status of cultural intermediary organizations in the minds of the public and enhance public awareness and trust of cultural intermediary organizations needs to establish a sound regulatory system. In order to build up the supervision system of connecting government cultural management department and the social media and the public mutual, governments can try to establish cultural intermediary organizations credit archives; the government cultural management departments specifically record cultural intermediary organizations and their employees credit rating, and regularly publish their credit information in the media, which facilitates the public to supervise the cultural intermediary organizations. It is also a good way to establish monitoring and reporting platform of cultural intermediary organizations, encourage social media and public to monitor business behavior of cultural intermediary organizations through network, telephone and other channels, and strengthen the behavior constraints of cultural intermediary organizations.

(2) Promote the Transformation of Government Functions, Strengthen the Development Vitality of Cultural Intermediary Organizations

With the continuous deepening of China's market economic system reform, many industries, before managed by the government sector, began to gradually pace toward market, and market-oriented degree gradually increased, which is the law of market economy and the demand of market development. In the past, the cultural industry of 
China has been under the control of the government, and the cultural industry mainly served the need of political propaganda. With the deepening of the market economy, the cultural industry has kept up with the pace of market economy and the market of cultural industry development. The marketization degree of cultural industries development has been continuously improved to meet the diversified needs of the cultural market. In the moment of strengthening the market mechanism in the cultural industry resource allocation and the decisive role of cultural intermediary organizations development, government departments should further deepen the functional transformation. First, The government department should clear the positioning of the status of cultural intermediary organizations and its functions and encourage the development of cultural intermediary organizations, while give cultural intermediary organizations a certain policy support at the same time. Internally, it is necessary to clarify the duties and objectives of cultural intermediary organizations, regulating their market operation mechanism and personnel behavior norms; Externally, there should be more publicity to the community, including the function, role and development level of cultural intermediary organizations, strengthen the public identity of cultural intermediary organizations. Second, the government should further improve the degree of marketization of cultural products and services, and delegate to cultural intermediary organization so that they can have more room for development. When encouraging the development of cultural intermediary organizations and giving policy support, government departments shouldn't make too much administrative intervention to hinder their market competition. Only having an adequate competition space, the cultural intermediary organization can play market potential.

(3) Construct Information Sharing Network Platform, Reduce Market Transaction Costs

The richness of market information and the difficulty of information collection are directly related to the direct costs of the development and operation of cultural intermediary organizations, so the real impact of cultural intermediary organizations operating efficiency is whether have ability to establish convenient information-sharing network platform between the various cultural subjects. As an important information capital and data resource sharing platform, large data has the potential to be fully utilized and shared by cultural intermediary organizations. Cultural intermediary organizations should stand on the national strategic level and attach great importance to establish large data information sharing network platform. Through moving data management forward, using a wide range of network channels to collect data and mining useful information will become the key breakthroughs of cultural intermediary organizations development. Cultural intermediary organizations should make full use of the large data management platform and introduce, innovate large data technology, establish and improve a large data management system, and achieve operation mode transformation, management capacity improving and technological innovation. Firstly, There should be perfecting the information management equipment of employees, and focusing in the upper-middle class with appropriate information training and management ability improving. In the lower class, It will have to update the organizational structure, increase professional and technical personnel and information gathering personnel, strengthen information management training; Secondly, to improve the application of large data facilities mainly means to provide infrastructure for large data information collection, such as large data software facilities, including algorithm updates, analytical methods and data processing methods to improve the multi-source data fusion analysis, etc. They are the key point of the market value to fully tap original cultural information and data of. By constructing large data network information platform, it will greatly enhance information collection ability and analysis and processing capacity of the cultural intermediary organization, thereby reducing the market transaction costs of cultural intermediary organizations and improving the operational capacity of cultural intermediary organizations.

(4) Build Cultural Talent Training System, Enhance International Cooperation in Cultural Industries

To promote the development of cultural intermediary organizations, it is necessary to strengthen the personnel training of cultural intermediary organizations and to guarantee the source power for the development of cultural intermediary organizations. The cultural department of the government should base on the strategic layout of cultural industry development and carry out scientific planning on the overall cultivation and development of cultural intermediary talents. From the aspects of training mode, hierarchical structure, capital investment and absorb the opinions from various parties, "cultural intermediary organizations talent development long-term planning" is formulated. That strengthens cultural intermediary organizations personnel training and team building from the strategic level, and strengthens the cultural intermediary group of personnel development policy support and top-level design. Perfecting cultural intermediary organization talent training mechanism can begin with following respects: The first is to construct the talent training model of all-round cultural intermediary organizations, which is market-oriented, university-based, enterprise-based and guided by the government and the industry. The second is to build a professional culture intermediary organization personnel training mode. Through creating the relevant professions and curriculum of cultural industries development and cultural intermediary organizations in colleges and universities to take full advantages of the cultural resources and personnel training; Enhancing the school-enterprise cooperation between cultural industry and cultural enterprises and establishing the cultivation mechanism of culture talents with the cooperation of production, study and research; using material resources of cultural enterprises and the advantages of practical platform to build a sound culture of innovative personnel training mode. Thirdly, we should strengthen the cooperation between our cultural intermediary organizations and international cultural industry organizations, fully absorb the advanced experience of the development of foreign cultural intermediary organizations, strengthen the joint training in cultural industry and intermediary organizations, strengthen the cultural industry information 
resources sharing and cultural product development exchange and other areas of cooperation to promote China's cultural intermediary organizations "bringing in" and "going out" strategy, improve the international level of cultural intermediary organizations and international competitiveness.

\section{Acknowledgements}

This thesis is supported by Social sciences planning project of Jiangxi province (No. 15GL17), Project name: Research on cultural intermediary organization of Jiangxi province: present development situation investigation and cultivating countermeasures.

\section{References}

[1] Liu jinxiang. Discuss the Cultivation and Development of Cultural Intermediary Organizations in China [J]. Journal of Zhejiang Shuren University, 2012 (3): 42-46.

[2] Liu jinxiang. Some Thoughts on Cultivation and Development of Cultural Intermediary Organizations in China [J]. Journal of CPC Ningbo municipal committee party school, 2012 (2): 75-79.

[3] Guo Guoqing, Chen Kai, Jiao Jialiang. The Study on the Problems and Countermeasures in the Development of Social Intermediary Organizations $[\mathrm{J}]$. Journal of China national school of administration, 2006 (1): 14.

[4] Gu Jiang. Opportunities and Challenges in the Development of Nanjing Cultural Intermediary Organizations [J]. Nanjing Social Sciences, 2003(2): 34.
[5] Zhu Jingwen, Sun Qing. Thinking about China's Cultural Intermediary Organizations [J]. Doctor Fourm, 2014.

[6] Yan Ping, Sun Qing. The Key Link of Cultural Intermediary and Cultural Industry Chain [J]. Learning Theory, 2008 (6).

[7] Ye Juan. Sun Qing. Cultural Intermediaries and German Cultural Policy [J]. Deutschland-studien, 2000 (4).

[8] Yang Aihua, Li Wenxue. The Role of Cultural Intermediary Organizations in Local Governmental Relationships [J]. Today's China Forum, 2007 (2): 2-3.

[9] Hu Pan. The Proposal for Cultural Intermediary Organizations in China [J]. Journal of Chongqign Institute of Socialism, 2007 (3): 6-8.

[10] Luo Jiahuan, Liu Dengling, Hu Wenya. Combine Blood Transfusion and Hematopoiesis Simultaneously-Discuss China 's Cultural Intermediary Organizations Behavior under the Government' s Effective Rules [J]. Journal of Postgraduates of Huazhong Normal University, 2009 (1): 12-15.

[11] Luo Jiahuan. Research on Intermediary Organizations and Governmental Regulation of Modern Culture in China - Taking Performing Arts Brokers as Main Body [D]. Central China Normal University, 2009.

[12] Sheng Yuzheng. Research on the Construction of Performance Indicators System of Provincial Public Cultural Service in China [D]. Zhejiang University, 2013.

[13] Du Honglin. Actively Develop Cultural Itermediary Organizations, and Promote the Prosperity of Cultural Industries [J]. Jiannan University, 2009, (11): 33-36.

[14] Lin Feng. Establish and develop the cultural industry intermediary organizations [J]. Objective Observing, 2003 (2): 45-47. 